\title{
Scintigraphic distribution of 123 I labelled proinsulin, split conversion intermediates and insulin in rats
}

\author{
F.Sodoyez-Goffaux ${ }^{1}$, J-C.Sodoyez ${ }^{1}$, M.Koch ${ }^{1}$, C.J.De Vos ${ }^{1}$ and B.H. Frank ${ }^{2}$ \\ ${ }^{1}$ Laboratory of Experimental Nuclear Medicine, University of Liege, Belgium and \\ ${ }^{2}$ Eli Lilly Research Laboratories, Indianapolis, Indiana, USA
}

\begin{abstract}
Summary. Insulin, biosynthetic human proinsulin and 2 human proinsulin conversion intermediates, des $(64,65)$ human proinsulin and des $(31,32)$ human proinsulin, were labelled with $123 \mathrm{I}$ and the derivatives monosubstituted on Tyr A14 were purified by reverse phase high performance liquid chromatography. The four tracers were injected into anaesthetized rats via a jugular or a portal vein and time activity curves were generated for the liver and kidneys using a gamma camera and an online computer. Liver extraction coefficients varied in the order insulin $(38 \%)$, des $(64,65)$ human proinsulin $(11.7 \%)$, des $(31,32)$ human proinsulin (3.2\%), human proinsulin (1.6\%); whereas half-life of hepatic
\end{abstract}

activity varied in the reverse order, from $6 \mathrm{~min}$ for insulin, to $45 \mathrm{~min}$ for human proinsulin. As expected for a non-receptor mediated process, kidney extraction varied conversely to liver extraction, being highest for human proinsulin and lowest for insulin. It is concluded that the kinetics of human proinsulin conversion intermediates depends upon the site of cleavage and deletion and is intermediate between those of insulin and intact human proinsulin.

Key words: Biosynthetic human proinsulin, conversion intermediates, 123-I-labelling, scintillation scanning.
Most of proinsulin is converted to insulin inside the $B$ cells of the pancreas, a process resulting from the interplay of several endopeptidases, different from trypsin itself [1-3]. Recently, two distinct site-specific endopeptidases regulated by calcium concentration and $\mathrm{pH}$ were identified in a $\mathrm{B}$ granule fraction of rat insulinoma [4]. During proinsulin processing, conversion intermediates are formed, in particular the split products des $(64,65)$ human proinsulin (HPI) and des $(31,32) \mathrm{HPI}$. These intermediates and intact HPI have been found in human sera [5], in insulin producing islet cell tumours [6-8] and in familial hyperproinsulinaemia [9-11]. Conversion to intermediates or insulin does not seem to occur after proinsulin enters the blood stream; partial conversion to intermediates might occur in the skin after subcutaneous injection [12].

From the standpoint of biological activity, proinsulin has remarkable characteristics. Compared to insulin, HPI has a low biological potency, a low avidity for insulin receptors and a prolonged half-life [13-17]. Moreover, the proinsulin conversion intermediates have been shown to exhibit greater biological activity than proinsulin itself, and this is particularly true for the conversion intermediate in which the $\mathrm{C}$ peptide/ $\mathrm{A}$ chain bond has been cleaved. Peavy et al. demonstrated that cleavage and/or dibasic amino acid deletions in the connecting peptide region of proinsulin enhance the receptor binding and hypoglycaemic activities of these compounds. In these studies, C peptide/A chain split products exhibited greater receptor affinity and hypoglycaemic activity than B chain C peptide split intermediates [18]. These observations prompted us to investigate the hepatic extraction and processing of HPI and its conversion products in vivo. For that purpose, we employed a previously described technique whereby the ligand-receptor interaction is studied in vivo, using a scintillation camera and $123 \mathrm{I}$ labelled ligand $[19,20]$.

\section{Materials and methods}

\section{Materials}

Human proinsulin was prepared utilising rDNA technology [21]. HPI split derivatives and human insulin (HI) were prepared by controlled enzymatic digestion of HPI. Bovine desoctapeptide insulin was also prepared by enzymatic digestion of bovine insulin. The structures of these derivatives were confirmed using amino acid 
analyses and amino acid sequencing. Solutions of insulin, HPI, HPI intermediates and desoctapeptide bovine insulin were prepared in $.01 \mathrm{~N} \mathrm{HC1}$ and calibrated by UV absorbance spectroscopy.

\section{Preparation of labelled molecules}

Human insulin $(0.1 \mathrm{mg})$ was labelled with $5-10 \mathrm{mCi} \mathrm{Na} 123 \mathrm{I}$ and the species monoiodinated on Tyr A14 was rapidly purified by isocratic reverse phase HPLC using a C18 Microbondapak column and a liquid phase containing $0.1 \mathrm{~mol} / 1$ tris phosphate $\mathrm{pH} 7$, $1 \mathrm{mmol} / 1$ EDTA and ethanol 39\%. An online UV detector monitored absorbance at $276 \mathrm{~nm}$ and activity of the $1 \mathrm{ml}$ fractions was measured using a Capintec dose calibrator. In this system, unreacted iodide is not retained and unlabelled insulin almost coelutes with the species monoiodinated on A19. These are followed by the 2 derivatives labelled on the $\mathrm{B}$ chain and finally, by the major radioactive peak corresponding to 123 I-Tyr A14-insulin [22].

Human proinsulin and the 2 split derivatives were similarly iodinated and the species substituted on A14 were purified in the same system by adapting ethanol concentration to the specific hydrophobicity of each molecule. Thus, the ethanol concentration of the elution buffer was $41 \%$ for HPI and $40.5 \%$ for des $(31,32)$ HPI and des $(64,65)$ HPI.

\section{Experimental procedure}

Fed Sprague-Dawley rats weighing $225-275 \mathrm{~g}$ were anaesthetized with pentobarbital $(60 \mathrm{mg} / \mathrm{kg}$ i.p.) and a PE 50 polyethylene tube was introduced into a jugular vein or a PE 10 tube into a branch of the portal vein. Rats were laid prone on the collimator of a scintillation camera connected to a computer (400 AT Maxicamera and „Star" computer, General Electric Medical Systems, Hoersholm, Denmark). Bolus injection of 123 I labelled hormone $(100 \mu \mathrm{Ci}$ in a volume of 0.3 to $0.6 \mathrm{ml}$ ) was performed immediately before recording sequential frames of $30 \mathrm{~s}$ for $30 \mathrm{~min}$.

\section{Computer analysis of sequential images}

Computer analysis of kinetic data was performed as follows. On the 6th frame, regions of interest (ROI) were drawn around whole rat (ROI 1), liver and the partly superimposed right kidney (ROI 2) and left kidney (ROI 3). Appropriate backgrounds were taken over the hip (ROI 4) and under the left kidney (ROI 5). Time activity curves were generated for each ROI and further treated to obtain net organ curves. The normalised hip (ROI 4) curve was subtracted from the liver + right kidney (ROI 2) curve. Net left kidney curve was similarly obtained after subtraction of the normalised background curve (ROI 5) from that generated from ROI 3. Based on the assumption that the 2 kidneys function in an identical manner, true liver time activity curve was calculated by subtracting the net left kidney curve from that of net liver + right kidney. Similarly, the total kidney time activity curve was calculated by multiplying net left kidney curve by 2.

Calibration of the ordinate of these curves was performed using counts measured on frame 6 . Counts (c) of ROI 1 were taken as $100 \%$. Percentages of activity in liver and kidneys at $3 \mathrm{~min}$ were calculated as follows:

liver activity, $\%=$

(c ROI2-normalised c ROI4)-(c ROI3-normalised c ROI5)

$$
\text { c ROI1 }
$$

Kidney activity, $\%=\frac{2(\mathrm{c} \text { ROI3-normalised c ROI5) }}{\text { c ROI1 }} \times 100$

\section{Liver extraction coefficients}

Knowing the liver activity profile after portal (LAp) and jugular (LAj) vein injection of a tracer, its hepatic extraction coefficient $(\alpha)$ can be calculated. Indeed, if the bolus is injected via the portal vein, a fraction of the tracer equal to $\alpha$ is retained during the first transhepatic pass. The remainder, $1-\alpha$, escapes the liver, reaches the right atrium and from thereon, is distributed as a bolus injected through a jugular vein. Thus, total liver activity after portal vein injection will be equal to the sum of activity retained during the first pass and of that retained after tracer recirculation and can be formulated as follows:

$\mathrm{LAp}=\alpha+(1-\alpha) \mathrm{LAj}$

In this first degree equation, there is only one unknown and $\alpha$ can easily be calculated.

\section{Statistical analysis}

Experimental groups injected with 123 I-HPI via portal or jugular vein numbered 9 rats each. All other experimental groups were composed of 8 animals. Mean and standard deviation of the 60 time points curves were calculated for each experimental group using standard computer programs.

Curves were then compared using the BMDP $2 \mathrm{~V}$ program of analysis of variance of repeated measures. $\log$ transformation of the variable was required to satisfy criteria of homoskedasticity [23].

\section{Results}

As shown by Figure 1, after bolus injection of $123 \mathrm{I}$ insulin through a jugular vein, the liver and kidneys became densely active within $3 \mathrm{~min}$. By contrast, under identical experimental conditions, 123 I-proinsulin was concentrated by the kidneys only. 123 I labelled HPI conversion intermediates displayed intermediate extraction by the liver, des $(64,65)$ HPI being extracted to a greater extent than the des (31, 32) HPI derivative.
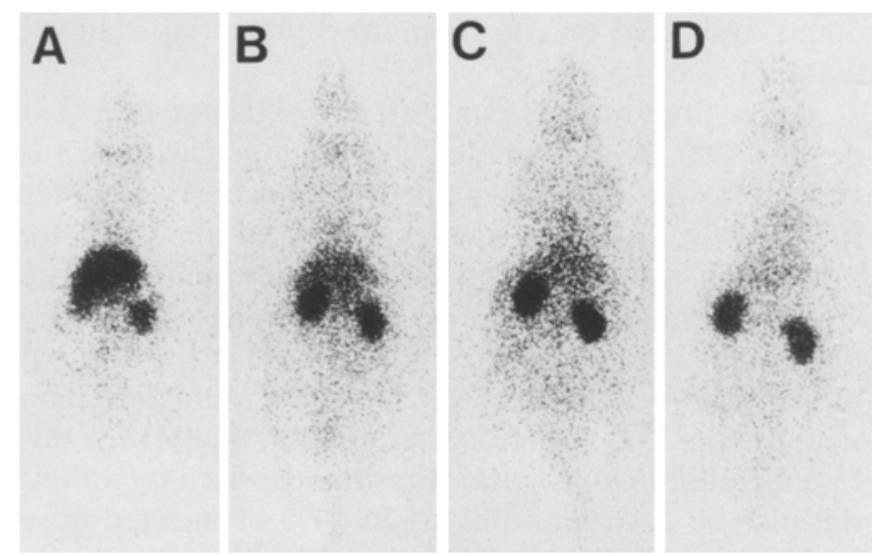

Fig. 1. Analogue images obtained 3 min after jugular vein injection of $100 \mu \mathrm{Ci} 123$ I-labelled insulin (A), des $(64,65) \mathrm{HPI}$ (B), des $(31,32)$ HPI (C) or intact HPI (D). Note that from left to right the liver image becomes fainter and the kidney images become denser 


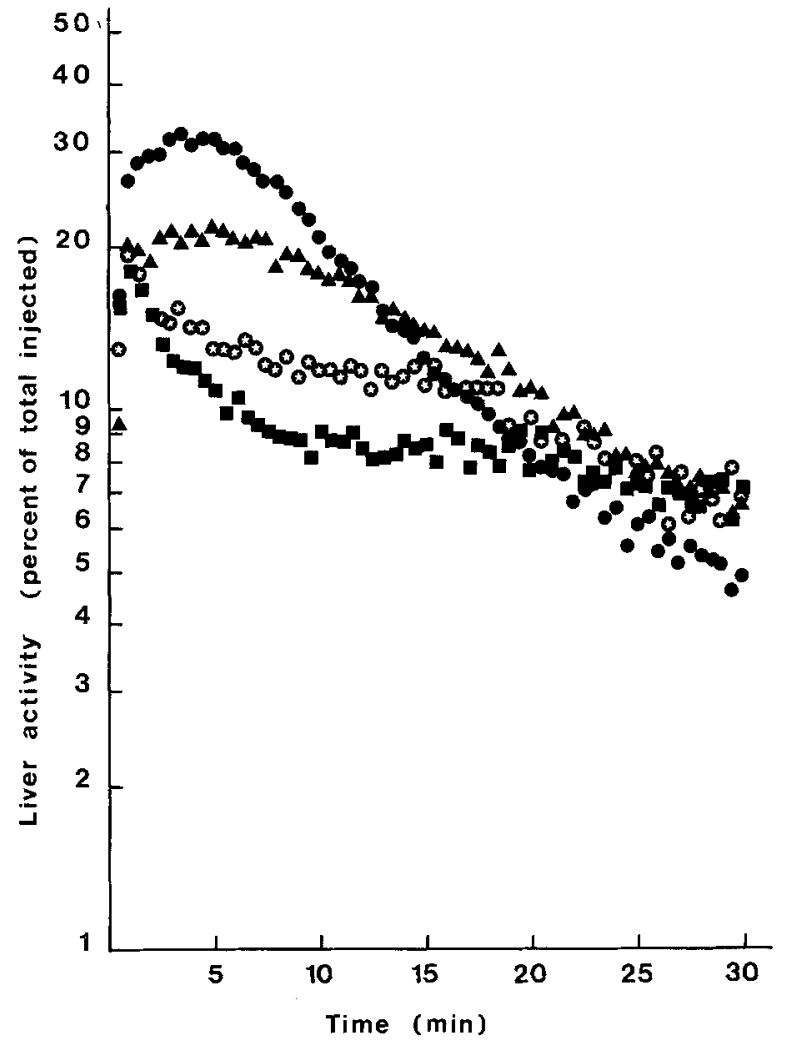

Fig. 2. Liver time activity curves after jugular vein injection of $100 \mu \mathrm{Ci} 123$ I-labelled insulin $(\mathbf{0}, n=8)$, des $(64,65)$ HPI $(\Lambda, n=8)$, des $(31,32)$ HPI $(\boldsymbol{\theta}, n=8)$ or intact HPI $(\boldsymbol{\square}, n=9)$

Differing liver extraction of the 4 molecules is further demonstrated by computer analysis of the dynamic recording (Fig. 2 and 4). After peripheral (jugular) vein injection, 123 I-insulin was rapidly concentrated by the liver, reaching $32.2 \pm 4.9 \%$ of injected dose (mean \pm SD) after 3.5 min (Fig. 2). After the 6th min, liver activity decreased in a semilog fashion ( $\mathrm{T} / 2=6 \mathrm{~min}$ ). In the presence of $123 \mathrm{I}$-HPI, liver activity decreased from $18 \pm 3 \%$ at 1 min to less than $10 \%$ at $6 \mathrm{~min}$ and later on, in an monoexponential manner, with a $\mathrm{T} / 2$ of $45 \mathrm{~min}$.

Liver time activity curve in the presence of $123 \mathrm{I}$ des $(31,32)$ HPI resembled that obtained with 123 IHPI but was slightly higher and decreased faster ( $p>0.05$ for difference of the means and $p<0.0001$ for interaction with time). Indeed, after an initial fall from $19.1 \pm 4.8 \%$ at $1 \mathrm{~min}$ to $13 \pm 3.2 \%$ at $5 \mathrm{~min}$, liver activity decreased with a half-life of $25 \mathrm{~min}$. The profile obtained with $123 \mathrm{I}$-des $(64,65)$ HPI was higher than with the des $(31,32)$ HPI derivative $(p<0.0001$ for difference of the means) and was characterised by an initial plateau corresponding to $20-21 \%$ of injected dose and lasting for $7 \mathrm{~min}$. Past this plateau, liver activity decreased with a half-life of $18 \mathrm{~min}(p<0.0001$ for interaction with time).

Kidney activity profiles of the same animals are illustrated in Figure 3. Kidney activity was the lowest

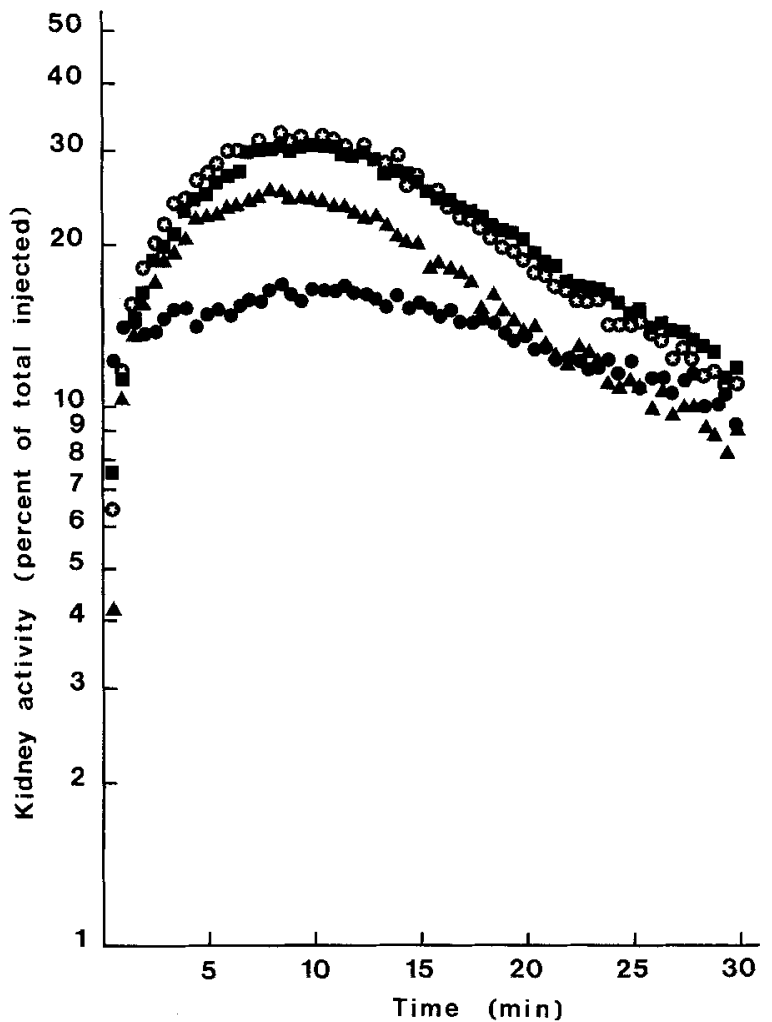

Fig. 3. Kidney time activity curves of the same animals as in Figure 2. Curves for HPI and des $(31,32)$ HPI were not statistically different but significantly higher than for des $(64,65)$ HPI $(p<0.0337)$. The profile of kidney activity was different after insulin and des $(64,65)$ HPI $(p<.0001$ for interaction with time). Symbols as in Figure 2

after $123 \mathrm{I}$-insulin, intermediate after $123 \mathrm{I} \cdot \operatorname{des}(64,65)$ HPI and the highest after 123 I labelled des $(31,32)$ HPI or HPI. For instance, at 5 min after peripheral (jugular) vein injection (Fig. 3), kidney activity, respectively, was $14.9 \pm 3.5,22.5 \pm 4.6,27.2 \pm 2$ and $25 \pm 3 \%$ for insulin, des $(64,65) \mathrm{HPI}$, des $(31,32) \mathrm{HPI}$ and intact HPI.

When the labelled molecules were injected via a branch of the portal vein, liver activity was higher than after peripheral vein injection, and the resulting gain in liver activity was lowest for HPI and highest for insulin (Fig. 4). Indeed, following 123 I-insulin injection, liver activity reached $55.1 \pm 4.6 \%$ of injected dose at $1 \mathrm{~min}$, remained at the same level until 4 or $4.5 \mathrm{~min}$ and then decreased with the previously defined half-life of $6 \mathrm{~min}$ $(p<0.0001$ for difference of the means and interaction with time between portal and jugular vein injection).

Liver activity profile was qualitatively similar with des $(64,65)$ HPI. However, the initial plateau corresponded to $29 \%$ of injected dose and lasted $5 \mathrm{~min}$ $(p<0.0026$ for difference of the means and $p<0.0001$ for interaction with time between portal and jugular vein injection). Subsequently, liver activity decreased monoexponentially, with a half-life of $18 \mathrm{~min}$. The difference of half-lives was so marked that the 2 activity profiles crossed around the 12th min. Time activity curves obtained after portal vein injection of 123 I-des 


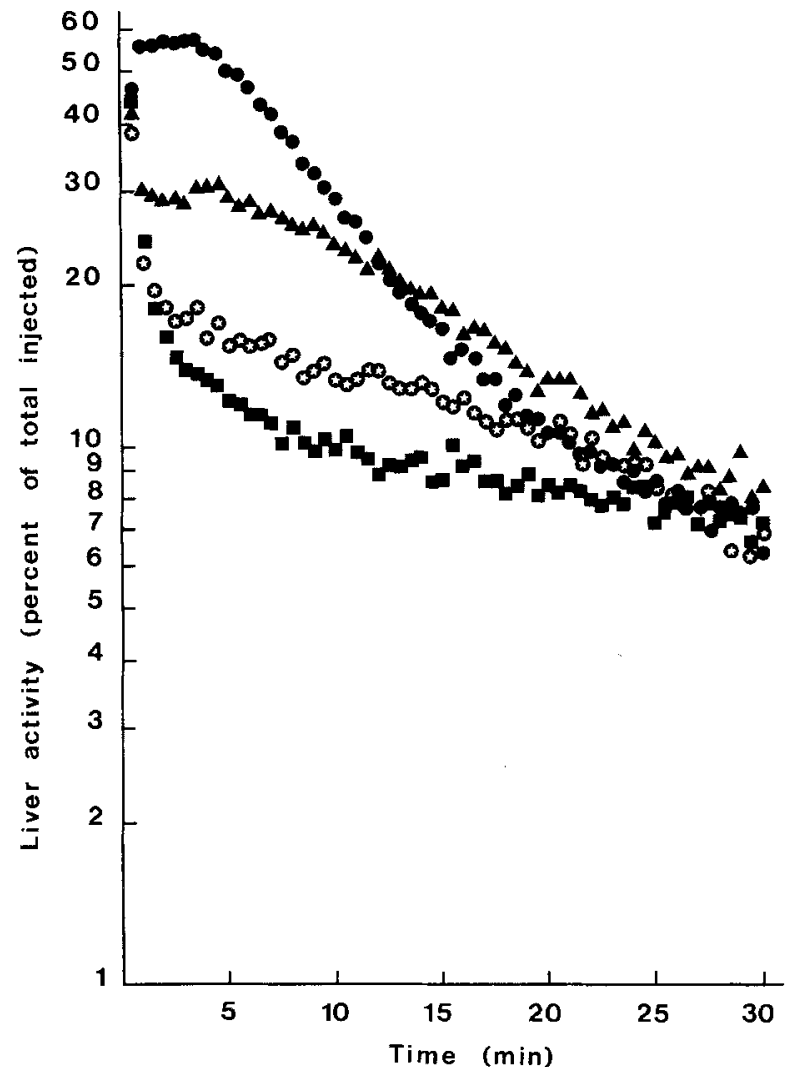

Fig. 4. Liver time activity curves after portal vein injection of $100 \mu \mathrm{Ci} 123$ I-labelled insulin $(\boldsymbol{\bullet}, n=8)$, des $(64,65)$ HPI $(\boldsymbol{\Lambda}, n=8)$, des $(31,32)$ HPI $(\cdots=8)$ and intact HPI $(\boldsymbol{\square}, n=9)$

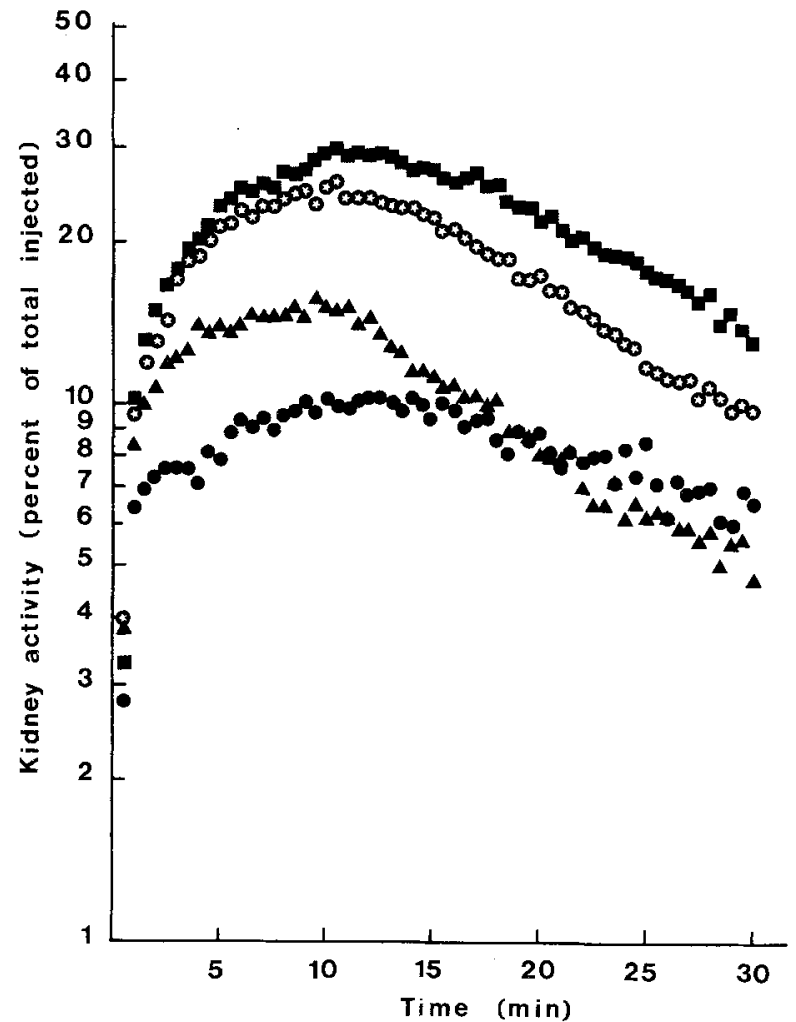

Fig. 5. Kidney time activity curves of the same animals as in Figure 4. Compared to jugular vein injection, portal vein injection decreased kidney activity for insulin $(p<0.002)$ and des $(64,65) \mathrm{HPI}$ $(p<0.001)$ but not for des $(31,32)$ HPI or intact HPI. Symbols as in Figure 4

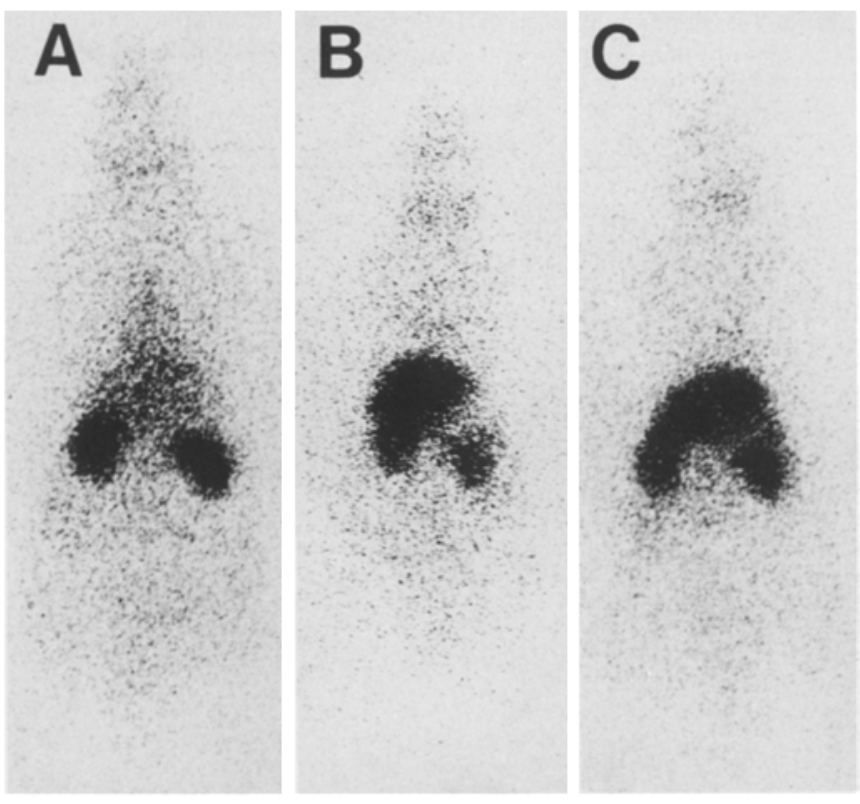

Fig. 6. Analogue images obtained 3 min after jugular vein injection of $100 \mu \mathrm{Ci} 123 \mathrm{I}$-insulin in rats pretreated with $20 \mu \mathrm{g}$ unlabelled insulin (A) or equimolar amounts of HPI (B) or bovine desoctapeptide insulin (C). Comparison of Figures 1 and 6 shows the following: (1) The Figure A image is similar to that illustrated in Figure 1 after injection of 123 I-HPI. In both cases, radioactivity was distributed independently of insulin receptors because these are saturated (A) or have a low affinity for the tracer (Fig.1, HPI). (2) The $\mathbf{B}$ and $\mathbf{C}$ images of Figure 6 are similar to the one shown in Figure 1 after injection of 123 I-insulin. In all 3 cases, the tracer was largely distributed in the specific receptor compartment because it is empty (Fig.1) or has a low affinity for the unlabelled competitor (panels $\mathbf{B}$ and $\mathbf{C}$ )

$(31,32)$ HPI and HPI were very similar to those obtained after peripheral vein injection of the same derivatives, although slightly higher $(p>0.05$ for difference of the means and $p<0.0001$ for interaction with time, between portal and peripheral vein injection, for both derivatives).

Portal vein injection decreased kidney activity to an extent commensurate to its enhancing effect on liver activity (Fig. 5). For instance, at $5 \mathrm{~min}$, kidney activity was reduced to $7.9 \pm 2.9,14.1 \pm 4,21.5 \pm 3.8$ and $23.2 \pm 4.4$ after 123 I-insulin, des $(64,65)$ HPI, des (31, 32) HPI and HPI respectively.

Comparison of liver activity following portal and peripheral vein injection allowed us to calculate that the liver extraction coefficients, respectively, were $1.6 \%, 3.2 \%, 11.7 \%$ and $38 \%$ for HPI, des $(31,32) \mathrm{HPI}$, des $(64,65)$ HPI and insulin (Table 1).

As shown by Figure 6, in rats pretreated with $20 \mu \mathrm{g}$ unlabelled insulin, liver uptake of 123 I-insulin was markedly decreased. Previous injection of an equimolar amount of unlabelled human proinsulin or bovine desoctapeptide insulin had a considerably lower inhibitory effect on 123 I-insulin liver uptake so that overall, the scintigraphic image was very similar to that observed in rats injected with $123 \mathrm{I}$-insulin alone (compare Fig.1 and 6). The very low potency of HPI is fur- 
Table 1. Characteristics of liver handling of human proinsulin, conversion intermediates and insulin

\begin{tabular}{lclc}
\hline & $\begin{array}{l}\text { Extraction } \\
\text { coefficient, } \alpha(\%)\end{array}$ & $\begin{array}{l}\alpha, \% \text { of that } \\
\text { of insulin }\end{array}$ & $\mathrm{T} / 2$, min \\
\hline Insulin & 38.0 & 100 & 6 \\
des 64, 65 split HPI & 11.7 & 30.8 & 18 \\
des 31, 32 split HPI & 3.2 & 8.4 & 25 \\
Human proinsulin & 1.6 & 4.2 & 45 \\
\hline
\end{tabular}

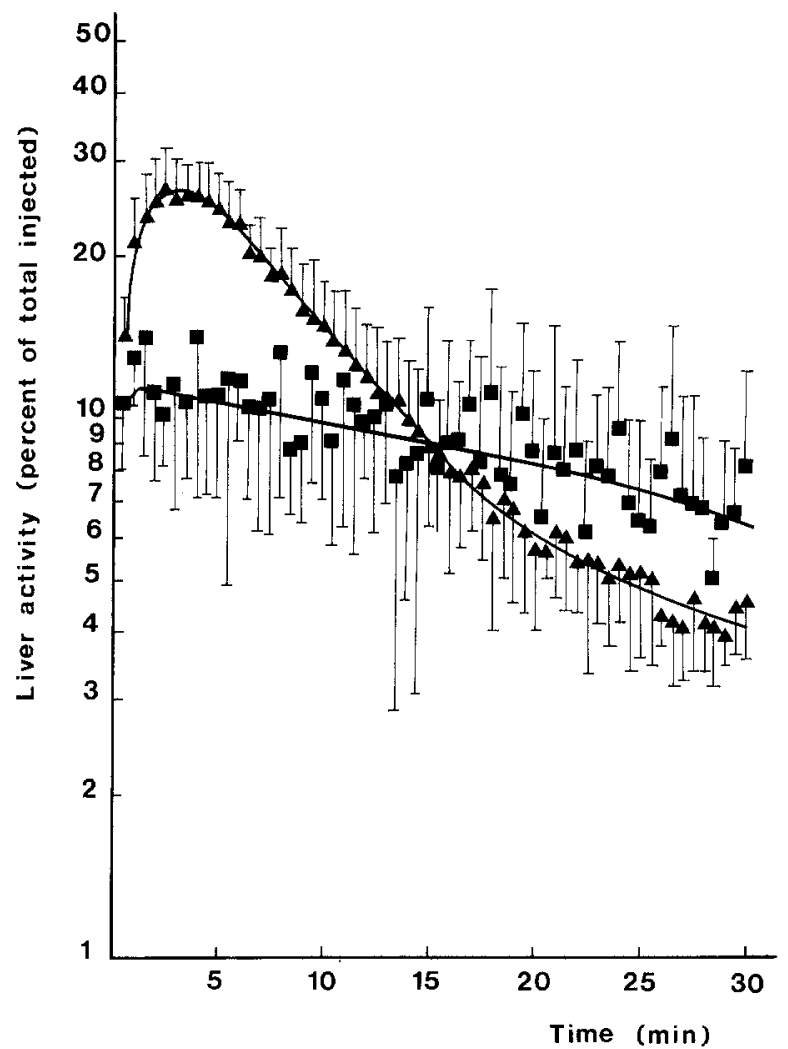

Fig. 7. Liver time activity curves after jugular vein injection of $100 \mu \mathrm{Ci} 123 \mathrm{I}$-insulin in rats pretreated with $20 \mu \mathrm{g}$ insulin $(\mathbf{E})$ or $30 \mu \mathrm{g}$ HPI (A). This dose of insulin was chosen because it occupies slightly over $50 \%$ of the receptor compartment [32]. Mean \pm SD; $n=8$ for each group. $p>0.05$ for identity of means and $p<0.0001$ for interaction with time

ther demonstrated by examination of the time activity curves. Indeed, at $3.5 \mathrm{~min}$, liver activity was $32 \pm 5 \%$ of injected dose after injection of 123 I-insulin alone (Fig. 2) and slightly reduced to $28 \pm 4 \%$, in the presence of unlabelled HPI (Fig.7) $(p<0.05$ for difference of the means). By contrast, prior injection of an equimolar amount of insulin resulted in occupation of most of the liver receptors so that $123 \mathrm{I}$-insulin binding was almost completely suppressed $(p<.0001$ for difference of the means). At $3.5 \mathrm{~min}$, liver activity was only $11 \pm 4 \%$ (Fig. 7 ).

\section{Discussion}

The methodology employed, labelling HI, HPI and its conversion intermediates with $123 \mathrm{I}$ and tracking these compounds in vivo by scintillation scanning, has ob- vious advantages and limitations. The two primary limitations are that: (1) Monoiodinated rather than native polypeptide must be used and (2) The camera detects radioiodine irrespective of its radiochemical form, whether it is attached to the original molecule, or to a fragment thereof, or whether it is free iodide.

Although heavy iodination has long been known to reduce biological potency and metabolic clearance rate of insulin, monoiodination, particularly on Tyr A14, carries little if any deleterious effect. In vitro, insulin monoiodinated on A14 has the same or a slightly higher potency than native insulin [24-26]. In vivo, monoiodinated insulin seems to be cleared as fast as native insulin although this is not fully agreed upon [27-30].

The second limitation of the technique - that organ activity does not differentiate between intact insulin, fragments of insulin or free iodide - is theoretically important. Therefore, results must always be critically interpreted and quantitation of uptake and degradation of insulin by selected organs must be regarded as approximate. Yet, a number of control experiments indicate that the technique yields acceptable approximations. As previously shown, labelled insulin is extracted by the liver by a receptor-mediated process. Indeed, hormone extraction is inhibited by previous saturation of the receptor compartment or by injection of anti-insulin receptor serum [19, 31]. Free radioiodide is the end product of monoiodoinsulin degradation. Free iodide is produced by dehalogenation of free monoiodotyrosine, originating from hydrolysis of monoiodoinsulin and not by dehalogenation of monoiodoinsulin itself [32]. Free iodide is rapidly transferred to the plasma and, therefore, contributes very little to liver radioactivity. By contrast to the liver, kidney uptake of $123 \mathrm{I}$-insulin largely proceeds by a non-saturable, nonreceptor mediated process [19, 31].

In the present study, we clearly demonstrate that, in vivo, HPI is a poor competitor for 123 I-insulin binding to the liver and that $123 \mathrm{I}$ labelled HPI has a low avidity for the liver receptors. Being weakly extracted by specific receptors, circulating HPI is essentially cleared by the kidneys [33-35]. Actually, scintigraphic images obtained after injection of 123 I-HPI are very similar to those obtained after injection of 123 I-insulin into rats whose receptor compartment has been fully occupied by "cold" ligand or blocked by specific anti-receptor antibodies [19, 31].

The present data indicate that proinsulin conversion intermediates are more efficiently extracted by liver receptors than intact HPI. Moreover, the C peptide/A chain intermediate displays greater affinity for the liver receptors than the $\mathrm{B}$ chain/C peptide derivative. Conversely to extraction by the liver, kidney uptake of the various molecules decreased in the order HPI $>$ des $(31,32)$ HPI $>$ des $(64,65)$ HPI $>$ insulin.

As shown here, by comparing the liver activity profiles after portal and peripheral vein injection, it is 
possible to calculate the liver extraction coefficients. The experimentally measured values indicated that, relative to insulin, affinity for liver receptors were, respectively, $4.2 \%$ for HPI, $8.4 \%$ for des $(31,32) \mathrm{HPI}$ and $30.8 \%$ for des $(64,65) \mathrm{HPI}$. These values are comparable to those measured in vitro using IM9 lymphocytes, rat adipocytes or liver plasma membranes [18].

Interestingly, intrahepatic half-lives vary conversely to liver extraction coefficients. Thus, HPI is extracted by the liver to the smallest extent but its hepatic half-life is the longest. The reverse is true for insulin. Conversion intermediates lay between these two extremes. Des $(31,32)$ HPI has properties very close to those of HPI itself. Des $(64,65)$ HPI is more interesting as its extraction by the liver is only one-third as fast as that of insulin but its intrahepatic half-life is 3-fold longer. These combined differences account for the fact that liver activity profiles obtained with labelled insulin and des $(64,65)$ HPI cross each other around the 12 th min.

As shown in isolated rat fat cells by Podlecki et al. HPI and HI are processed with different kinetics [36]. A recent work (Duckworth et al., personal communication) indicates that rat fat cells convert biosynthetic HPI to intermediates cleaved in the region of the B chain (residues 23-24) or of the connecting peptide (residues 55-56) but not to insulin. It is tempting to speculate that slow degradation of internalised material and, proteolytic cleavage without conversion to insulin, also occur in other target tissues and are applicable to HPI conversion intermediates as well as to intact HPI.

Circulating HPI has a decreased metabolic clearance rate and a 3 to 4 -fold longer half-life than insulin $[16,17]$. Furthermore, HPI has a weak but remarkably prolonged hypoglycaemic effect in vivo, which has been attributed to its prolonged circulating half-life. The present data suggest that prolonged intrahepatic half-life may also contribute to prolong the hypoglycaemic effects of proinsulin and of proinsulin conversion intermediates.

In conclusion, 123 I-HPI was extracted weakly by the liver and extensively by the kidneys. Splitting and deletions at either one extremity of the $C$ peptide had differing effects. Indeed splitting at the $\mathrm{Al}$ region generated an intermediate with higher affinity for the liver receptors than splitting at the B30 region. Des $(64$, 65) HPI was, however, less potent than insulin itself. Intrahepatic half-lives varied conversely to hepatic extraction, from $45 \mathrm{~min}$ for HPI to $6 \mathrm{~min}$ for insulin itself.

Acknowledgements. These studies were supported by grants from the National Lottery and FRSM (Brussels, Belgium) and the Faculty of Medicine of the University of Liege (Liege, Belgium). We thank Mrs. M. Hoste-Fodor for secretarial assistance and Ch. Fallais (IRE, Fleurus, Belgium) for the generous supply of Na-123 I. We would also like to thank Mr. A. Pekar for preparation of HPI conversion intermediates used in this study.

\section{References}

1. Kemmler W, Steiner DF, Borg J (1973) Studies on the conversion of proinsulin to insulin. III. Studies in vitro with a crude secretion granule fraction isolated from rat islets of Langerhans. J Biol Chem 248: 4544-4551

2. Fletcher DJ, Quigley JP, Bauer GE, Noe BD (1981) Characterization of proinsulin- and proglucagon-converting activities in isolated islet secretory granules. J Cell Biol 90: 312-322

3. Docherty K, Carroll RJ, Steiner DF (1982) Conversion of proinsulin to insulin: involvement of a 31,500 molecular weight thiol protease. Proc Natl Acad Sci USA 79: 4613-4617

4. Rhodes CJ, Davidson HW, Zumbrunn A, Shaw E, Hutton JC (1988) Proinsulin to insulin conversion is mediated by two distinct site specific endopeptidases that are regulated by $\mathrm{Ca}^{++}$ and $\mathrm{pH}$. Diabetologia 31: $535 \mathrm{~A}$

5. de Haën C, Little SA, May JM, Williams RH (1978) Characterization of proinsulin-insulin intermediates in human plasma. $\mathrm{J}$ Clin Invest 62: 727-737

6. Creutzfeldt C, Track NS, Creuzfeldt W (1973) In vitro studies of the rate of proinsulin and insulin turnover in seven human insulinomas. Eur J Clin Invest 3: 371-384

7. Gutman RA, Lazarus NR, Penhos JC, Fajans S, Recant L (1971) Circulating proinsulin-like material in patients with functioning insulinomas. N Engl J Med 284: 1003-1008

8. Sherman BM, Pek S, Fajans SS, Floyd JC Jr, Conn JW (1972) Plasma proinsulin in patients with functioning pancreatic islet cell tumors. J Clin Endocrinol Metab 3: 271-280

9. Gabbay KH, Bergenstal RM, Wolff J, Mako ME, Rubenstein AH (1979) Familial hyperproinsulinemia: partial characterization of circulating proinsulin-like material. Proc Natl Acad Sci USA 76: 2881-2885

10. Robbins DC, Blix PM, Rubenstein AH, Kanazawa Y, Kosaka K, Tager HS (1981) A human proinsulin yariant at arginine 65. Nature 291: 679-681

11. Robbins DC, Shoelson SE, Rubenstein AH, Tager HS (1984) Familial hyperproinsulinemia: two families secreting indistinguishable type II intermediates of proinsulin conversion. J Clin Invest 73: 714-719

12. Given BD, Cohen RM, Shoelson SE, Frank BH, Rubenstein AH, Tager HS (1985) Biochemical and clinical implications of proinsulin conversion intermediates. J Clin Invest 76: 1398-1405

13. Freychet $P$ (1974) The interactions of proinsulin with insulin receptors on the plasma membrane of the liver. J Clin Invest 54: 1020-1031

14. Revers RR, Henry R, Schmeiser L Kolterman O, Cohen R, Bergenstahl R, Polonsky K, Jaspan J, Rubenstein AH, Frank B, Galloway J, Olefsky JM (1984) The effects of biosynthetic human proinsulin on carbohydrate metabolism. Diabetes 33: $762-770$

15. Henry R, Schmeiser L, Kolterman O, Cohen R, Rubenstein A, Frank B, Galloway J, Olefsky JM (1984) Biosynthetic human insulin and proinsulin have additive but not synergistic effects on total body glucose disposal. J Clin Endocrinol Metab 58: 1094-1098

16. Stoll RW, Touber JL, Winterscheid LC, Ensinck JW, Williams RH (1971) Hypoglycemic activity and immunological halflife of porcine insulin and proinsulin in baboons and swine. Endocrinology 88: 714-717

17. Starr JI, Rubenstein AH (1974) Metabolistn of endogenous proinsulin and insulin in man. J Clin Endocrinol Metab 38: 305-308

18. Peavy DE, Brunner MR, Duckworth WC, Hooker CS, Frank BH (1985) Receptor binding and biological potency of several split forms (conversion intermediates) of human proinsulin. Studies in cultured IM9 lymphocytes and in vivo and in vitro in rats. J Biol Chem 260: 13989-13994

19. Sodoyez JC, Sodoyez-Goffaux F， Guillaume M, Merchie G (1983) 123-I-insulin metabolism in normal rats and humans: external detection by a scintillation camera. Science $219: 865-867$ 
20. Verdin EM, Marathos-Flier E, Kahn CR, Sodoyez JC, SodoyezGoffaux F, De Vos CJ, Lynn SP, Fields BN (1987) Visualization of viral clearance in the living animal. Science 236: 439-442

21. Frank BH, Pettee JM, Zimmerman RE, Burck PJ (1981) Peptides, structure and function. Pierce Chemical Company, Illinois, pp 729-738

22. Sodoyez JC, Sodoyez-Goffaux F (1988) Studies of insulin receptors in vivo, using 123 -I-insulin and scintillation scanning. In: Kahn CR, Harrison LC (eds.) Insulin receptors. Part B: Clinical assessment, biological responses and comparison to the IGF-1 Receptor. Alan R Liss, New York, pp 135-151

23. Dixon WI, Brown MB (eds) (1981) BMDP Biomedical Computer Programs. University of California Press, Berkley Los Angeles London

24. Linde S, Hansen B, Sonne O, Holst JJ, Gliemann J (1981) Tyrosine A14 $125 \mathrm{I}$ monoiodoinsulin preparation, biologic properties and long term stability. Diabetes $30: 1-8$

25. Frank BH, Peavy DE, Hooker CS, Duckworth W (1983) Receptor binding properties of monoiodotyrosyl insulin isomers purified by high performance liquid chromatography. Diabetes 32 : 705-711

26. Jorgensen KH, Moody AJ, Christensen MC (1982) Evidence that monoiodo-(A14)-insulin is more potent than insulin in the rat free fat cell assay. Abstract 11th Congress IDF, Nairobi

27. Sherwin RS, Kramer KJ, Tobin JD, Insel PA, Liljenquist JE, Berman M, Andres R (1974) A model of the kinetics of insulin in man. J Clin Invest 53: 1481-1492

28. Terris S, Steiner DF (1976) Retention and degradation of 125-Iinsulin by perfused livers from diabetic rats. J Clin Invest 57 $885-896$

29. Ferrannini E, Pilo A (1979) Pattern of insulin delivery after intravenous glucose injection in man and its relation to plasma glucose disappearance. J Clin Invest 64: 243-254
30. Cockram CS, Jones RH, Boroujerdi MA, Sönksen PH (1984) Evidence for separate handling in vivo of different regions of the insulin molecule using A14- and B1-labeled insulin tracers. Diabetes 33: 721-727

31. Sodoyez JC, Sodoyez-Goffaux F, Von Frenckell R, De Vos CJ, Treves S, Kahn CR (1985) Differing effects of antiinsulin serum and antiinsulin receptor serum on 123-I-insulin metabolism in rats. J Clin Invest 75: 1455-1462

32. Sodoyez JC, Sodoyez-Goffaux FR, Moris YM (1980) 125 I-insulin. Kinetics of interaction with its receptors and rate of degradation in vivo. Am J Physiol 239: E3-E11

33. Katz AI, Rubenstein AH (1973) Metabolism of proinsulin, insulin, and C-peptide in the rat. J Clin Invest 52: 1113-1121

34. Rubenstein AH, Pottenger LA, Mako M, Getz GS, Steiner DF (1972) The metabolism of proinsulin and insulin by the liver. J Clin Invest 51: 912-921

35. Rabkin R, Ross BD, Mako ME, Rubenstein AH (1978) The handling of insulin, proinsulin, and C-peptide by the isolated rat kidney. Diabetes 27 [Suppl. 1]: 192-196

36. Podlecki DA, Frank BH, Olefsky JM (1984) In vitro characterization of biosynthetic human proinsulin. Diabetes 33: 111-118

Received: 22 June 1988

and in revised form: 26 September 1988

Dr. J. C. Sodoyez

Department of Internal Medicine

University of Liege

CHU, Sart Tilman

B-4000 Liege

Belgium 